\section{Viral mimicry: common mode of association with HCF by VP16 and the cellular protein LZIP}

\author{
Richard N. Freiman ${ }^{1,2}$ and Winship Herr ${ }^{1,3}$ \\ ${ }^{1} \mathrm{C}$ old Spring Harbor Laboratory, Cold Spring Harbor, N ew \\ York 11724 USA; ${ }^{2}$ Graduate Program in Genetics, State \\ University of N ew York, Stony Brook, N ew York 11794 USA
}

\begin{abstract}
Upon infection of human cells, the herpes simplex virus protein VP16 associates with the endogenous cell-proliferation factor HCF. VP16 can also associate with HCFs from invertebrates, suggesting that VP16 mimics a celIular protein whose interaction with HCF has been conserved. Here, we show that VP16 mimics the human basic leucine-zipper protein LZIP, which, through association with HCF, may control cell-cycle progression. VP16 and LZIP share a tetrapeptide motif-D/E HXYused to associate with human HCF. The LZIP-related D rosophila protein BBF-2/ dCREB-A contains this HCFbinding motif, indicating that the LZIP-HCF interaction has been conserved during metazoan evolution.
\end{abstract}

Received August 25, 1997; accepted in revised form September 18, 1997.

The initiation of herpes simplex virus (HSV) infection involves the interaction of viral and cellular proteins. The HSV virion carries the viral transactivator VP16 (al so known as Vmw65 and $\alpha \mathrm{TIF}$ ), which is rel eased into the cell upon infection and associates with two cellular factors-HCF and Oct-1-to initiate a cascade of viral gene expression (for review, see Thompson and McKnight 1992; O'Hare 1993). VP16 first associates with HCF (also known as C1, VCAF, and CFF), a protein involved in cell proliferation (Goto et al. 1997). HCF binding to VP16 promotes subsequent association with the POU DNA-binding domain of the transcription factor Oct-1 on the cis-regulatory target of VP16 activation: the TAATGARAT motif found in HSV immediate-early promoters. The interplay between viral and cellular elements afforded by this VP16-induced complex provides a mechanism for coordination of HSV infection with the state of the infected cell.

VP16 interacts with each of the other components in the VP16-induced complex, the DNA, Oct-1, and HCF. Two of these interactions, however, are not highly conserved: VP16 from different herpesviruses differs in its DN A-binding specificity (Huang and Herr 1996; M isra et al. 1996), and VP16 associates poorly with mouse Oct-1, which differs from human Oct-1 on the surface of the POU domain critical for association with VP16 (Cleary et al. 1993; Suzuki et al. 1993).

In contrast, the VP16-HCF interaction is highly con-

[Key Words: HCF protein; VP16; LZIP; protein-protein interactions; transcription]

${ }^{3}$ Corresponding author.

E-MAIL her@@cshl.orgs FAX (516) 367-8454. served: HCF from organisms as different as vertebrates and invertebrates can associate with VP16 and stabilize the VP16-induced complex (Kristie et al. 1989; Wilson et al. 1993b). This conservation suggests that VP16 mi mics a cellular protein whose interaction with HCF is essential for viability in metazoans. Here, we describe the isolation of such a candidate: the human basic leucine zipper (bZIP) protein LZIP. Strikingly, LZIP and a related Drosophila protein called BBF-2 (Abel et al. 1992) or dCREB-A (Smolik et al. 1992) share with VP16 a short tetrapeptide motif used to associate with HCF.

\section{Results}

HCF is synthesized as a large precursor protein of $\sim 2000$ amino acids, which is subsequently processed by proteolysis at multiple sites into amino- and carboxy-terminal fragments, which remain noncovalently bound (Wilson et al. 1993a, 1995b; Kristie et al. 1995). VP16 associates with a 380-residue amino-terminal domain of HCF, called the HCF $\mathrm{VIC}_{\mathrm{C}}$ domain (Wilson et al. 1997). To identify human proteins that bind the HCF $\mathrm{VIIC}_{\mathrm{V}}$ domain, we used the yeast two-hybrid assay (Fiel ds and Song 1989) to screen a human HeLa cell cDN A library for proteins able to associate with a GAL4 DNA-binding domain (DBD) fusion to the first 450 residues of $\mathrm{HCF}\left(\mathrm{DBD} \cdot \mathrm{HCF}_{\mathrm{N} 450}\right)$.

We identified three (out of $1 \times 10^{6}$ ) clones that interact specifically with $\mathrm{HCF}_{\mathrm{N} 450}$. All three clones were derived from the same human gene, encoding a bZIP protein related to the mouse protein LZIP, a protein of little known biological function (Burbel o et al. 1994). We refer to the human protein as human LZIP or hLZIP. A contemporaneous study by Lu et al. (1997) also identified LZIP (referred to as Luman in that study) in a two-hybrid screen for human HCF-interacting proteins.

Figure 1A shows the specificity of the $\mathrm{HCF}_{\mathrm{N} 450}-\mathrm{hLZIP}$ interaction. Neither the $\mathrm{DBD} \cdot \mathrm{HCF}_{\mathrm{N} 450}$ fusion protein nor a GAL4 transcriptional activation domain hLZIP fusion (AD - hLZIP) activates the Gal 1-His3 reporter on its own (sectors $A$ and $E$, respectively) or together with an irrelevant partner (sectors $B$ and $F$, respectively). $\mathrm{DBD} \cdot \mathrm{HCF}_{\mathrm{N} 450}$ does, however, activate the GAL1-HIS3 reporter in the presence of $A D \cdot h L Z I P$ (sector $D$ )-as does a VP16 activation domain fusion protein $(A D \cdot V P 16$; sector $C)$-demonstrating specific $\mathrm{HCF}_{\mathrm{N} 450}$ interaction with LZIP.

Figure $1 \mathrm{~B}$ compares the sequences of human and mouse LZIP. Basic DNA-binding and leucinezipper dimer-formation regions typical of bZIP proteins are located in the center of LZIP. These regions are 93\% identical between human and mouse LZIP and include unusually long leucine-zi pper segments with seven imperfect leucine heptad repeats. Outsi de of the basic leucinezipper region, the sequences are of similar size but display less sequence identity.

In a N orthern hybridization analysis (data not shown; see al so Lu et al. 1997), hLZIP mRN A was detected in all tissues tested, suggesting that, like HCF (Wilson et al. 1995a), hLZIP is broadl y expressed. Figure $1 C$ shows that the natural human HCF and LZIP proteins associate 
with one another: Immunoprecipitation from a human 293-cell extract with an anti-HCF antibody (lane 2), but not with a nonspecific antibody (lane 1), resulted in recovery of endogenous LZIP as evidenced in an immunoblot with anti-LZIP antisera.

The HCF tsBN67 cell proliferation mutant fails to interact with LZIP

HCF is involved in promoting cell proliferation: A single proline-to-serine substitution at position 134 (P134S) of the $\mathrm{HCF}_{\mathrm{VIC}}$ domain causes a temperature-sensitive cell cycle arrest (Goto et al. 1997) and disrupts the ability of VP16 to bind HCF (Wilson et al. 1997). If VP16 mimics LZIP, LZIP should associate with the minimal 380-residue $\mathrm{HCF}_{\mathrm{VIC}}$ domain $\left(\mathrm{HCF}_{\mathrm{N} 380}\right)$, and the tsBN 67 mutation should prevent association. Figure 2 shows that these predictions are correct: In the two-hybrid assay, VP16 and LZIP both interact with wild-type $\mathrm{HCF}_{\mathrm{N} 380}$ (sectors $\mathrm{B}$ and $C$, top) but not tsBN $67 \mathrm{HCF}_{\mathrm{N} 380}$ (sectors $B$ and $C$, bottom), even though both the wild-type and tsBN $67 \mathrm{HCF}$ fusion proteins were expressed at similar levels as determined by immunoblot analysis (data not shown). The tsBN 67 effect on LZIP association makes LZIP a candidate target of HCF in controlling cell proliferation.

\section{LZIP and VP16 associate similarly with the HCF $F_{V I C}$ domain}

To contrast VP16 and LZIP association with the HCF $_{V I C}$ domain more extensively, we assayed the effects of a systematic set of point mutations in the HCF $F_{V I C}$ domain on HCF association with VP16 and LZIP. The HCF $F_{V I C}$ domain consists of six sequence repeats related to a repeat motif found in the Drosophila protein Kelch, which are called $\mathrm{HCF}_{\mathrm{KEL}} 1$ to $\mathrm{HCF}_{\mathrm{KEL}} 6$ (Wilson et al. 1997). Sequence similarity to other proteins suggests that Kelch repeats form four-stranded $\beta$-sheets which come together to form a propeller-like structure, called a $\beta$-propeller, in which each repeat resembles a blade of the propeller (Bork and Doolittle 1994). The P134S tsBN 67 mutation replaces a proline in $\mathrm{HCF}_{\mathrm{KEL}} 3$ that is uni versal ly conserved in all six repeats (Wilson et al. 1997) without affecting HCF stability in vivo (Goto et al. 1997) or protease sensitivity in vitro (R. Freiman and W. Herr, unpubl.).

B

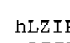
II:LZIP hLZIP antibody.
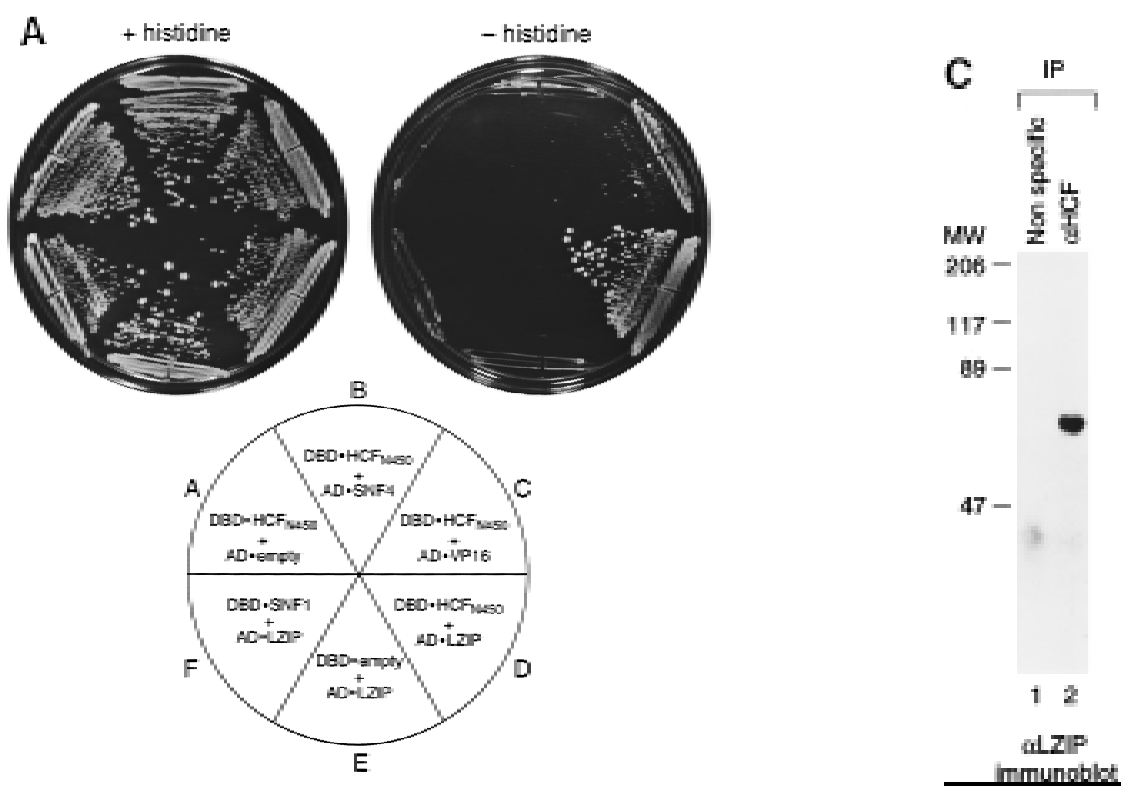
MELELDAGDQDLLAFLLEESGDLGTAPDEAVRAPLDWALPLSEVP-1/9-1 $\overrightarrow{-4-1}$ MDPGGQDL.A..P.............WA.TEPD.K.S. LE.SF . NSVQEL............SV.RDV.G HBM

LLZIP SSNPCLVHHDHTYSLPRETVSMDLESESCRKEGTOMTPOHMEE-LAEQEIARLVLTDEEKSLLEKEGLILPETLPLTK 145

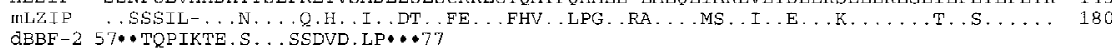

BASIC REGION

LEUCINE ZIPPER

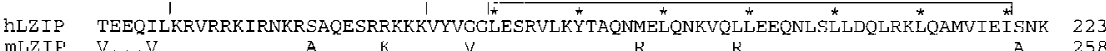

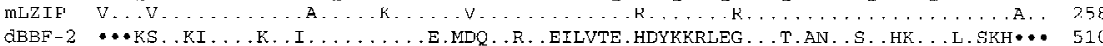

LLZIP TSSSSTCILVLLVSECLLLVPAMYSSDTRGSLPAEHGVLSROLRALPSEDPYQLELPALQSEVPKDSTHQWLDGSDCV 301

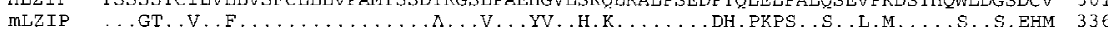

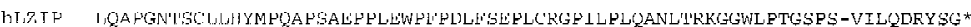
MLZIP

Figure 1. The bZIP protein LZIP interacts specifically with HCF. (A) Y east two-hybrid assays showing specificity of the HCF-LZIP interaction. Growth of the yeast GAL1HIS3 reporter strain transformed with both a Gal4 DN A-binding domain (DBD) fusion expression plasmid and a Gal4 activation domain (AD) fusion expression plasmid is shown. The identity of the fusion constructs is indicated in the diagram. Growth with histidine (thistidine) demonstrates that the expression plasmids are not deleterious to yeast growth, and growth without (-histidine) demonstrates activation of the GAL1HIS3 reporter gene. The yeast were grown for 7 days at $30^{\circ} \mathrm{C}$ in both the presence and absence of histidine. (B) A mino acid sequence comparison of human LZIP (hLZIP) with mouse LZIP (mLZIP; Burbel o et al . 1994) and two regions of the LZIP-rel ated Drosophila protein BBF-2/dCREB-A (A bel et al. 1992; Smolik et al. 1992, label ed dBBF-2). Sequence identities to hLZIP are indicated by dots in the comparison. The DNA-binding basic region and dimerization-interface leucine zipper are bracketed, with an asterisk above the seven hydrophobic residues that make up the extended leucine zipper of LZIP. The location of an additional 25 amino acids introduced by an alternate splice variant of mouse LZIP (Burbelo et al. 1994) is indicated ( $\boldsymbol{\nabla})$. The AD fusion points of the original two-hybrid screen isolates are indicated by the arrows above the top line. (HBM) HCFbinding motif. (C) Association of endogenous HCF and LZIP from human cells. Human 293 whole-cell nuclear extracts were precipitated with the nonspecific 12CA 5 influenza hemagglutinin monoclonal antibody (lane 1) or the M 2 anti-HCF monoclonal antibody (lane 2), and immunoblots of the precipitates were probed with the C7 LZIP antipeptide

Therefore, we assayed the effects of substituting the corresponding proline in each $\mathrm{HCF}_{\mathrm{KEL}}$ repeat with alanine on association with LZIP and VP16, as shown in Figure 3.

Consistent with VP16 mimicry of the LZIP interaction 
with $\mathrm{HCF}$, the $\mathrm{HCF}_{\mathrm{KEL}}$ repeat substitutions had paral lel effects on VP16 and LZIP association: Substitution of the conserved proline in $\mathrm{HCF}_{\mathrm{KEL}} 1$ and $\mathrm{HCF}_{\mathrm{KEL}} 5$ had no evident effect on either LZIP or VP16 interaction with HCF (sectors $A$ and $E$ ), demonstrating that substitution of this universal ly conserved prol ine by al anine does not necessarily lead to universal disruption of the $\mathrm{HCF}_{\mathrm{VIC}}$ domain structure. The $\mathrm{HCF}_{\mathrm{KEL}} 2$ and $\mathrm{HCF}_{\mathrm{KEL}} 6$ substitutions had an intermediate effect on LZIP and VP16 interaction (sectors $\mathrm{B}$ and $\mathrm{F}$ ); only the $\mathrm{HCF}_{\mathrm{KEL}} 3$ and $\mathrm{HCF}_{\mathrm{KEL}} 4$ substitutions prevented effective LZIP or VP16 interaction with the $\mathrm{HCF}_{\mathrm{VIC}}$ domain (sectors $\mathrm{C}$ and $\mathrm{D}$ ). The dominant effects of the mutations in $\mathrm{HCF}_{\mathrm{KEL}} 3$ and $\mathrm{HCF}_{\mathrm{KEL}} 4$ suggest that LZIP and VP16 bind the HCF $F_{V I C}$ domain assymetrically.

LZIP and VP16 share a tetrapeptide motif important for association with HCF

VP16 and LZIP display little sequence similarity (data not shown). There is, however, similarity to a short sequence in VP16-EHAY - that is involved in HCF association (Haigh et al. 1990; Hayes and O'H are 1993; Wu et al. 1994; Simmen et al. 1997; Lai and Herr 1997). As shown in Figure 4A, this sequence is conserved in VP16 homol ogs from different herpesviruses, forming the consensus sequence ${ }^{D} /{ }_{E} H X Y$, where the first position can be either aspartic or glutamic acid and the third position is variable. The human and mouse LZIP sequences share this tetrapeptide consensus [see Fig. 1B (labeled HBM) and Fig. 4A].

To test the functional significance of this tetrapeptide motif in LZIP, we compared the effect of individual substitutions in a 9-amino-acid segment encompassing the human LZIP and HSV VP16 $/{ }_{\mathrm{E}} \mathrm{HXY}$ motifs on association with HCF. To measure association, we as-
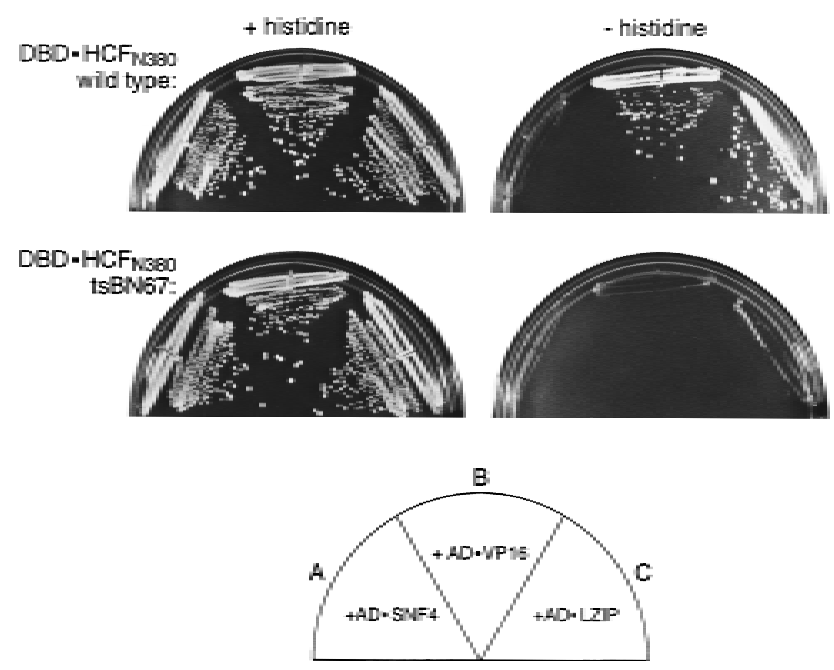

Figure 2. The HCF tsBN 67 cell-cycle arrest mutation disrupts interaction with LZIP. Y east two-hybrid interaction assays with wild-type $\mathrm{HCF}_{\mathrm{N} 380}\left(\mathrm{DBD} \cdot \mathrm{HCF}_{\mathrm{N} 380}\right.$, top panels) and tsBN 67 $\mathrm{HCF}_{\mathrm{N} 380}\left(\mathrm{DBD} \cdot \mathrm{HCF}_{\mathrm{N} 380} \mathrm{P} 134 \mathrm{~S}\right.$, bottom panels) were performed as indicated in the diagram. The yeast were grown for 5 days at $30^{\circ} \mathrm{C}$ in both the presence (left) and absence (right) of histidine.
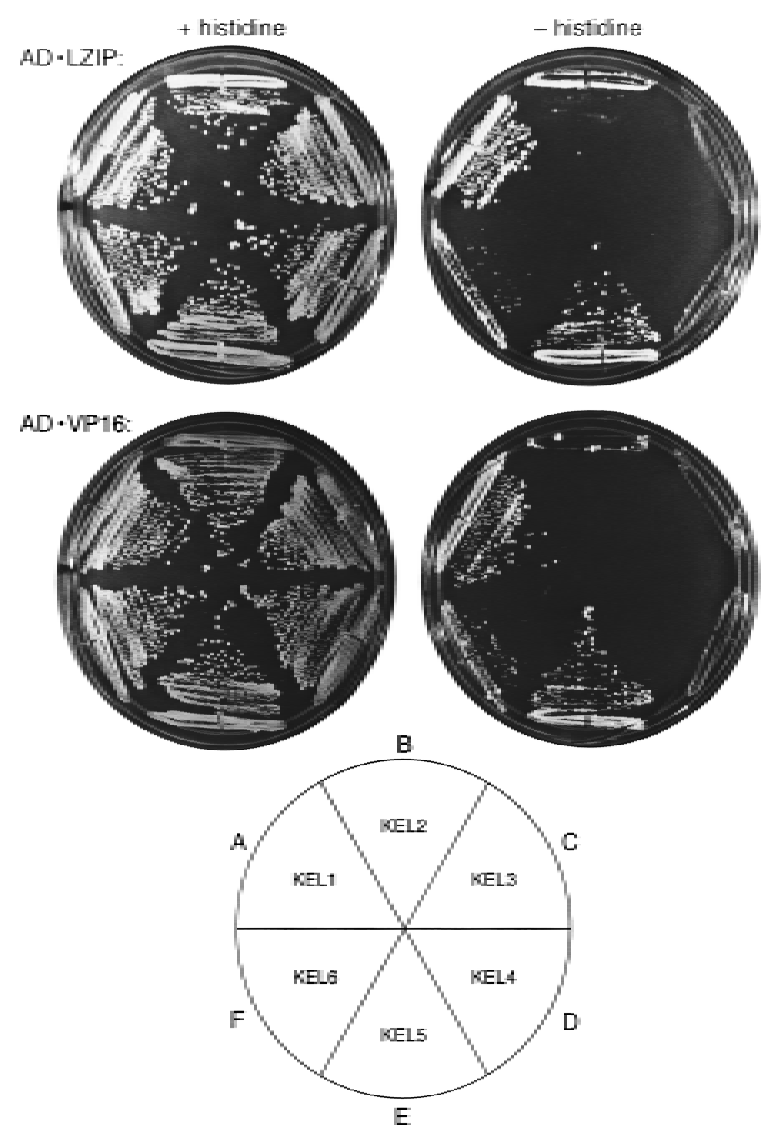

DED- HCF FEL Mutant

Figure 3. LZIP and VP16 recognize HCF similarly. Yeast twohybrid interactions between mutated $\mathrm{HCF}_{\mathrm{N} 380}$ and LZIP (top) and VP16 (bottom). The DBD $\cdot \mathrm{HCF}_{\mathrm{KEL}}$ 1-6 mutants (see diagram) contain individual proline-to-al anine substitutions as follows: KEL1, P30A; KEL2, P79A; KEL3, P134A; KEL4, P197A; KEL5, P252A; KEL6, P319A. The yeast were grown for 7 days at $30^{\circ} \mathrm{C}$ in both the presence (left) and absence (right) of histidine. A control with wild-type DBD $\cdot \mathrm{HCF}_{\mathrm{N} 380}$ with $\mathrm{AD} \cdot \mathrm{LZIP}$ and $A D \cdot V P 16$ grown in parallel showed the same growth rate as the cells grown in sectors $A$ and $E$.

sayed coimmunoprecipitation of epitope-tagged wildtype and mutant LZIP and VP16 proteins with endogenous HCF after transient expression in human 293 cells, as shown in Figure 4B. Direct epitope tag immunoblot analysis of the extracts showed that the mutant LZIP and VP16 proteins were expressed at levels similar to their wild-type counterparts (lanes 1-10). Little protein, however, was recovered after immunopreci pitation with an irrelevant antibody (lanes 21-30). Strikingly, with both human LZIP and HSV VP16, mutation of the same three positions-the first, second, and fourth positions of the $\mathrm{D} / \mathrm{E}_{\mathrm{E}} \mathrm{HXY}$ motif-interfered with $\mathrm{HCF}$ association, whereas mutation of the other residues, including the variable third position in the ${ }^{\mathrm{D}} /{ }_{\mathrm{E}} \mathrm{HXY}$ motif, did not prevent LZIP or VP16 association with HCF (lanes 11-20). These results suggest that VP16 mimics a small motif in LZIP-an HCF-binding motif (HBM) - to promote association with HCF. Consistent with this hypothesis, VP16 and LZIP compete with one another 
for association with HCF (Lu et al. 1997; C. Grozinger, R. Freiman, and W. Herr, unpubl.).

\section{$\mathrm{A} /{ }_{\mathrm{E}} \mathrm{HXY}$ motif in Drosophila BBF-2 promotes association with HCF}

The ability to interact with VP16 is shared by metazoan HCFs (Kristie et al. 1989; Wilson et al. 1993b), suggesting that the HCF interaction with a cellular protein mimicked by VP16 is conserved in vertebrates and invertebrates. To test this hypothesis, we asked whether human HCF can associate with an LZIP-related protein from Drosophila. The known Drosophila protein most closely related to LZIP is the bZIP protein BBF-2 (Abel et al. 1992; also called dCREB-A, Smolik et al. 1992); this protein is $81 \%$ identical to human LZIP in the basic region and shares an extended imperfect leucine-zipper segment as shown in Figure 1B. Outside of the bZIP region, BBF-2 shares only limited similarity to the mammalian LZIP proteins, but it does contain a consensus D/ ${ }_{E} \mathrm{HXY}$ motif near its amino terminus as shown in Figures $1 \mathrm{~B}$ and $4 \mathrm{~A}$. Therefore, using the same assay shown in Figure 4B, we tested native human $\mathrm{HCF}$ association with both wild-type BBF-2 and a BBF-2 mutant containing a single al anine substitution of the first position of the $\mathrm{D} /{ }_{\mathrm{E}} \mathrm{HXY}$ motif, as shown in Figure $4 \mathrm{C}$. In contrast to wild-type and mutant human LZIP, a low level of wild-type and mutant BBF-2 was re covered in the immunoprecipitation with the irrelevant antibody (lanes 5-8). N everthel ess, wild-type LZIP and BBF-2 proteins were re covered more effectively than the mutant forms after coprecipitation with HCF (cf. lanes 1 and 2, and 3 and 4), suggesting that HCF can associate with BBF-2 through a D/ ${ }_{\mathrm{E}} \mathrm{HXY} \mathrm{HCF}$-binding motif. Together, the sequence similarity be tween LZIP and BBF-2 and their common mode of interaction with HCF suggest that LZIP and BBF-2 are homologs serving similar functions in mammals and insects, such as promoting cell proliferation.
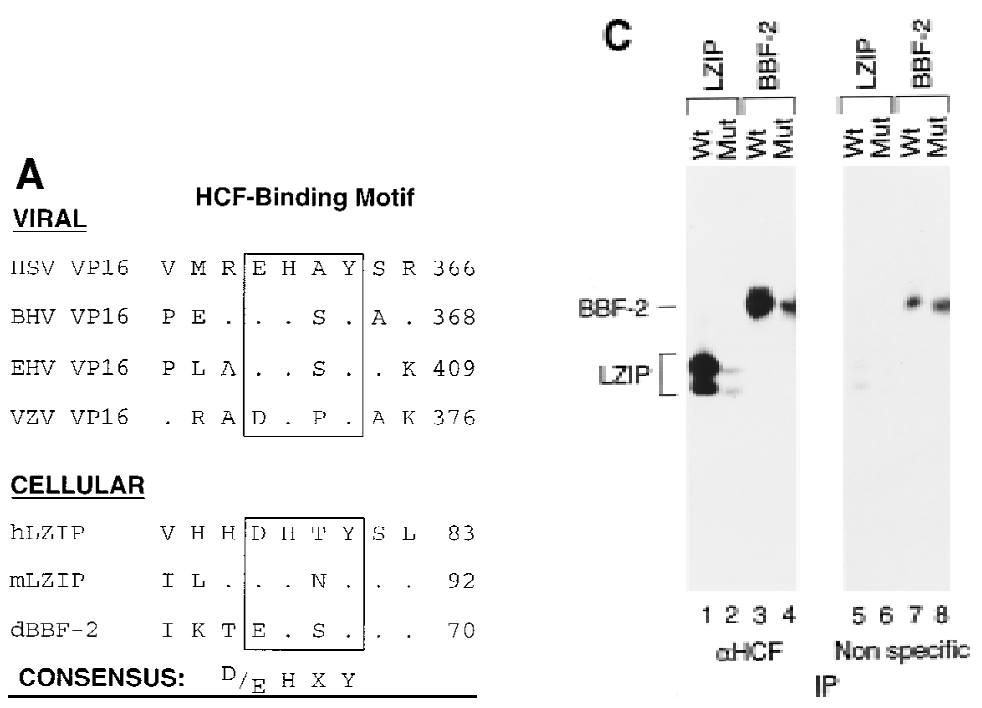

B

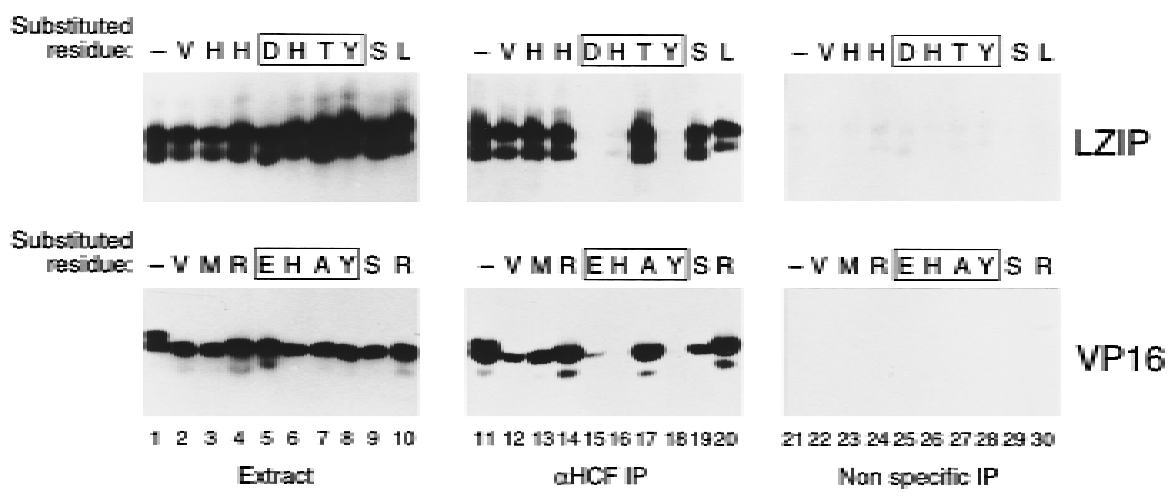

Figure 4. Mammalian LZIP, Drosophila BBF-2, and VP16 share a small HCF-binding motif. (A) HCF-binding motif sequence al ignment. The VP16 sequences are derived from homologs of VP16 from bovine herpesvirus (GenBank accession no. Z54206; BTIF), equine herpesvirus (GenBank accession no. L16590), and varicella-zoster virus (GenBank accession no. X04370; ORF 10). Dots indicate sequence identities with the HSV VP16 (viral) and hLZIP (cellular) sequences shown. The position of the carboxy-terminal residue within the parental sequence is indicated to the right. The HCF-binding motif is boxed and a consensus is shown at the bottom. (D/E) Either aspartic or glutamic acid; $(X)$ nonconserved variable residue. (B) HCF association with wild-type and mutant LZIP and VP16. Epitopetagged wild-type or nine substitution mutants of LZIP (top panels) and VP16 (bottom panels) were transiently expressed in human 293 cells. The mutated resi due in each mutant is indicated above each lane. In LZIP, all residues were changed to al anine, except for the threonine, which was changed to asparagine. In VP16, all nonalanine residues were changed to alanine, and the alanine was changed to serine. Expression of each mutant protein is shown by direct immunoblot with the anti-T 7 epitope antibody of the 293 cell extract (lanes 1-10). Extracts were precipitated with the N $18 \mathrm{HCF}$ antipeptide antibody (Ianes 11-20) or the nonspecific anti-N -Oct-3 antibody (lanes 21-30). In each panel, LZIP or VP16 was detected by immunobl ot analysis with the anti T7 epitope tag antibody. (C) HCF recognizes the Drosophila BBF-2 HCF-binding motif. T 7-epitope-tagged wild-type and mutant LZIP and BBF-2 were transiently expressed in human 293 cells. Position 1 of the HCF-binding motif in LZIP (D to A) and BBF-2 (E to A) were mutated (Mut). 293 cell extracts were immunoprecipitated with the N 18 HCF antibody (lanes 1-4) or the nonspecific anti-N-Oct-3 (lanes 5-8) and the precipitates analyzed by immunoblot with the antiT7 epitope tag antibody. Direct immunobl ot with the anti T7 epitope tag antibody showed that for both LZIP and BBF-2 the wild-type and mutant proteins were expressed at the same level, but the BBF-2 proteins were expressed at higher levels than LZIP (data not shown). 


\section{Discussion}

We have identified related human and Drosophila bZIP proteins that associate with the cell proliferation factor HCF. The HSV regulatory protein VP16 mimics how these proteins-LZIP in humans and BBF-2 in Drosophila-associate with HCF: Like LZIP and BBF-2, VP16 contains a short $\mathrm{D} / \mathrm{E} \mathrm{HXY}$ HCF-binding motif, and LZIP and VP16 interactions with HCF are similarly affected by mutations in HCF, including the temperaturesensitive cell-cycle arrest mutation tsBN 67. Because LZIP and BBF-2 interact with HCF similarly and VP16 copies this interaction, perhaps the conserved LZIP and BBF-2 interaction with HCF is the proposed conserved cellular interaction mimicked by VP16. The association with a bZIP protein implicates HCF in regulating cellular as well as viral patterns of gene transcription.

The common association with HCF suggests that LZIP and BBF-2 are human and Drosophila homologs. Consistent with this hypothesis the basic region DNA-binding domains of LZIP and BBF-2 are closely related, and both proteins contain unusually long and imperfect leucinezipper segments (see Fig. 1B). The cl osest rel ated proteins to LZIP and BBF-2 are CAMP response el ement-binding (CREB) and activating transcription factor 1 (ATF-1) in mammals and dCREB-B in Drosophila (for review, see Hurst 1995), suggesting that the HCF-interacting LZIP and BBF-2 proteins are members of a subfamily of bZIP proteins that includes the CREB/ATF-1-related proteins. Interestingly, both LZIP and CREB associate with large nuclear proteins: HCF in the case of LZIP, and the transcriptional coregulator CREB-binding protein (CBP) in the case of CREB (Chrivia et al. 1993).

Although LZIP can bind to CREB- and other bZIPbi nding sites (Burbel o et al . 1994; Lu et al. 1997; C. Grozinger, R. Freiman, and W. Herr, unpubl.), the natural targets of LZIP regulation are unknown. In Drosophila, the natural targets of transcriptional regulation by BBF-2 are also not well understood, al though disruption of the BBF2/dCREB-A gene in Drosophila has specific effects on embryonic development (Andrew et al. 1997; Rose et al . 1997). Because LZIP fails to associate with the HCF cellcycle arrest mutation tsBN 67, LZIP may be involved in regulating cell-cycle progression together with HCF. tsBN 67 cells arrest in a $_{0^{-}}$or early $G_{1}$-like state, which implicates HCF in preventing entry into $G_{0}$ and/or promoting passage through early $G_{1}$ (Goto et al. 1997). Thus, genes involved in progression through $G_{0}$ and early $G_{1}$ are attractive targets of LZIP regulation.

One of the characteristics of the HCF tsBN 67 phenotype is a delay of one or a few cell divisions before stable growth arrest occurs (Goto et al. 1997). The implication of HCF association with a transcription factor to regulate cell-cycle progression offers an explanation for this phenotype: HCF and LZIP regulate-by activation or repression-expression of a gene whose product regulates cellcycle progression; when the HCF or LZIP interaction is disrupted at the nonpermissive temperature by the tsBN 67 mutation, the HCF-LZIP-regulated gene product has to be depleted or inactivated before cell-cycle arrest can occur.
Unlike obligate lytic viruses, HSV can undergo either a productive lytic infection or remain latent for long periods. VP16, which is important for initiating the cascade of HSV gene expression that results in productive infection, may serve as a sensor by which the virus is able to coordinate virus replication with the cell-cycle or differentiation state of the infected cell. The requirement for productive association with two cellular factors, Oct-1 and HCF, before VP16 can initiate HSV immediate-early gene transcription suggests that it may be these interactions with which VP16 senses the status of the cell. The studies described here suggest that in both cases VP16 is targeting the cellular transcriptional machinery: It associates with Oct-1, a POU domain transcription factor involved in histone and small nucl ear RN A gene expression, and HCF, which is now implicated in regulating transcription through association with LZIP. VP16 may target the cellular transcriptional apparatus because this machinery changes rapidly as it responds to or directs changes in cell status.

\section{Materials and methods}

Yeast two-hybrid interaction assay

The GAL4 DNA-binding domain fusion expression plasmid pGBT 9, containing the TRP1 gene, was used to construct GAL4 DBD fusions (residues 1-94) to $\mathrm{HCF}$ (the pGDBD-HCF series). pGDBD-HCF $\mathrm{N}_{450}$ $\left(\mathrm{DBD} \cdot \mathrm{HCF}_{\mathrm{N} 450}\right)$ and $\mathrm{pGDBD}-\mathrm{HCF}_{\mathrm{N} 380}\left(\mathrm{DBD} \cdot \mathrm{HCF}_{\mathrm{N} 380}\right)$ contain human $\mathrm{HCF}$ residues 2-450 and 2-380, respectively. pGDBD-HCF 450 was used to screen a human HeLa cDN A-GAL4 activation domain (AD; residues 768-881) fusion library constructed in pGADGH, which contains the LEU 2 gene (a gift of G. Hannon, Cold Spring Harbor Laboratory). Both the $D B D$ and $A D$ plasmids were cotransformed in the reporter strain Hf7c containing both GAL4-responsive his3 and lacZ reporter genes. Yeast $\left(1 \times 10^{6}\right)$ transformants were screened for $\mathrm{His}^{+}$growth. Of $41 \mathrm{His}^{+}$ colonies recovered after $7-10$ days growth at $30^{\circ} \mathrm{C}$ on synthetic media plates lacking trytophan, leucine, and histidine, only 5 displayed activation of the lacZ reporter. The AD plasmids were recovered from these five positives and retransformed into the reporter strain YGH1. Only three clones (3-1, 4-1, and 9-1) activated the Gal1-His3 reporter in the presence but not in the absence of the $\mathrm{HCF}_{\mathrm{N} 450}$ bait. Plasmids expressing the GAL4 DBD (DBD - empty) or AD al one (AD - empty), or fused to the yeast proteins SNF1 (DBD - SNF1) and SNF4 (AD - SNF4) were used as negative controls (Fields and Song 1989).

Cloning full-length human LZIP

Sequence analysis reveal ed that two of the three HCF-interacting fusion proteins were identical and that all three were AD fusions to either residue 43 (3-1 and 9-1) or 54 (4-1) of the same mouse LZIP-related gene (Burbelo et al. 1994). The full-length LZIP CDNA was cloned by PCR amplification of a human $\lambda$ gt10 phage CDNA library with two nested LZIP-specific primers and one $\lambda$-specific primer. The extended 5 ' sequence reveal ed an in-frame initiator ATG codon; the sequence has been deposited in GenBank (accession no. AF029674)

Plasmid constructions and mutagenesis

The GAL4 DBD-HCF fusion constructs-the pGDBD-HCF series-are all derived from pGBT 9 but only encode GAL4 residues 1-94. This AD fusion vector, pGADGHX2, a pGADGH derivative for in-frame insertion of Xbal-BamHI fragments, was used to create pGADGHVP16 $\Delta C$ (AD - VP16), which contains VP16 residues 5-412 lacking the carboxyterminal VP16 activation domain, and pGADGHLZIP $F$ (AD - LZIP) which contains LZIP residues 2-371. In Figure $1 A$, the AD - LZIP construct contains residues 43-371 (clone 3-1). T7-epitope-tagged VP16, LZIP, and BBF-2 were expressed from pCGT plasmids. VP16 was expressed from pCGTVP16 $\Delta$ C (Wilson et al. 1997). pCGTLZIP ${ }_{F L}$ contains $\mathrm{hLZIP}$ residues $2-371$, and $\mathrm{pCGTBBF-} \mathrm{2}_{\mathrm{FL}}$ contains Drosophila BBF-2 residues 2-515. A mino acid substitutions were generated by oligonucleotidedirected mutagenesis as described previously (Kunkel et al. 1987). 
Antisera and immunoprecipitation

The C 7 anti-LZIP antiserum was rai sed in rabbits against the octapeptide CLQDRYSG containing the carboxy-terminal 7 amino acids of hLZIP (underlined) coupled to keyhole limpet hemocyanin and inoculated into rabbits as described (Atanasoski et al. 1997). The N 18 anti-peptide HCF (Goto et al. 1997) and N-Oct 3 (Atanasoski et al. 1997) antisera and M 2 anti-HCF monoclonal antibody (Wilson et al. 1995a) have been described previously. To assay endogenous HCF and LZIP interaction, human 293 extracts were prepared in extraction buffer $(200 \mathrm{mM} \mathrm{KCl}, 100 \mathrm{mM}$ Tris at pH 8.0, 10\% glycerol, 0.1\% N P-40, 20 mM EDTA, and 1 mM PMSF). A 1:50 dilution of the anti-HCF monoclonal antibody M 2 (Wilson et al. 1995a) was incubated with the extract for $90 \mathrm{~min}$ at $4^{\circ} \mathrm{C}$ with rotation. Immune complexes were recovered with protein $\mathrm{G}$-agarose beads, washed four times in the same buffer without glycerol and $0.05 \%$ N P-40, and resolved by $12 \%$ SDS-PAGE for immunoblot analysis. A 1:1000 dilution of the C7 LZIP antiserum was used to probe the immunoblot.

Transient expression, coprecipitation, and immunoblotting

To express T 7 epitope-tagged LZIP, VP16, and BBF-2 proteins, pCGTL$\mathrm{ZIP}_{\mathrm{FL}}(20 \mu \mathrm{g})$, pCGTVP16 $\Delta \mathrm{C}(0.2 \mu \mathrm{g})$, and pCGTBBF- $2_{\mathrm{FL}}(2.0 \mu \mathrm{g})$ were transfected into human 293 cells by electroporation, and extracts pre pared $36 \mathrm{hr}$ post-transfection as described (Wilson et al. 1997) in $1 \mathrm{ml}$ of extraction buffer containing $1.0 \% \mathrm{~N} \mathrm{P}-40,0.5 \%$ DOC, and $0.1 \%$ SDS. The anti-HCF N 18 or anti-N-Oct 3 polyclonal sera were cross-linked to protein A-agarose as described (Harlow and Lane 1988). Ten microliters of antibody beads ( $50 \%$ slurry) was added to $200 \mu$ lof extract and incubated for $90 \mathrm{~min}$ at $4^{\circ} \mathrm{C}$, recovered by centrifugation, and washed three times in extraction buffer. Immune complexes were resolved on a $10 \%$ SDSPAGE and immunobots probed with the anti-T 7 epitope tag monoclonal antibody ( $\mathrm{N}$ ovagen) at a 1:5000 dilution. The levels of T 7 epitope-tagged LZIP and VP16 expression were assayed by direct immunoblotting of $1 / 20$ and $1 / 100$ of the extract, respectively.

\section{Acknowledgments}

We thank A. Wilson and T. Nishimoto for helpful discussions and for sharing results prior to publication; G. Hannon and L. Van Aelst for advice and reagents for the yeast two-hybrid assay; $B$. Ren and T. M aniatis for a BBF-2-encoding CDNA clone; D. Aufiero for technical assistance; N. Hernandez for critical reading of the manuscript; and J. Duffy, M. Ockler, and P. Renna for artwork. This study was supported by U.S Public Health Service grant CA13106 from the National Cancer Institute.

The publication costs of this article were defrayed in part by payment of page charges. This article must therefore be hereby marked "advertisement" in accordance with 18 USC section 1734 solely to indicate this fact.

\section{References}

A bel, T., R. Bhatt, and T. M aniatis. 1992. A Drosophila CREB/ATF transcriptional activator binds to both fat body- and liver-specific regulatory elements. Genes \& Dev. 6: 466-480.

Andrew, D.J., A. Baig, P. Bhanot, S.M. Smolik, and K.D. Henderson. 1997 The Drosophila dCREB-A gene is required for dorsal / ventral patterning of the larval cuticle. Development 124: 181-183.

Atanasoski, S., E. Schreiber, A. Fontana, and W. Herr. 1997. N-Oct 5 is generated by in vitro proteolysis of the neural POU-domain protein N-Oct 3. Oncogene 14: 1287-1294.

Bork, P. and R.F. Doolittle. 1994. Drosophila kelch motif is derived from a common enzyme fold. J. Mol. Biol. 236: 1277-1282.

Burbelo, P.D., G.C. Gabriel, M.C. Kibbey, Y. Yamada, H.K. Kleinman, and B.S. Weeks. 1994. LZIP-1 and LZIP-2:two novel members of the bZIP family. Gene 139: 241-245.

Chrivia, J.C., R.P. Kwok, N. Lamb, M. Hagiwara, M.R. Montminy, and R.H. Goodman. 1993. Phosphorylated CREB binds specifically to the nuclear protein CBP. Nature 365: 855-859.

Cleary, M.A., S. Stern, M. Tanaka, and W. Herr. 1993. Differential positive control by Oct-1 and Oct-2: activation of a transcriptionally siIent motif through Oct-1 and VP16 corecruitment. Genes \& Dev. 7: $72-83$.

Fields, S. and O. Song. 1989. A novel genetic system to detect proteinprotein interactions. Nature 340: 245-246.

Goto, H., S. M otomura, A.C. Wilson, R.N. Freiman, Y. Nakabeppu, K
Fukushima, M. Fujishima, W. Herr, and T. Nishimoto. 1997. A single-point mutation in HCF causes temperature-sensitive cellcycle arrest and disrupts VP16 function. Genes \& Dev. 11: 726-737.

Haigh, A., R. Greaves, and P. O'H are. 1990. Interference with the assembly of a virus-host transcription complex by peptide competition. Nature 344: 257-259.

Harlow, E. and D. Lane. 1988. Antibodies: A laboratory manual. Cold Spring Harbor Laboratory, Cold Spring Harbor, NY.

Hayes, S. and P. O'Hare. 1993. M apping of a major surface-exposed site in herpes simplex virus protein $V m w 65$ to a region of di rect interaction in a transcription complex assembly. J. Virol. 67: 852-862.

Huang, C.C. and W. Herr. 1996. Differential control of transcription by homologous homeodomain coregulators. Mol. Cell. Biol. 16: 29672976.

Hurst, H.C. 1995. Transcription factors 1:bZIP proteins. Protein Profile 2: $105-168$.

Kristie, T.M., J.H. Lebowitz, and P.A. Sharp. 1989. The octamer-binding proteins form multi-protein-DNA complexes with the HSV a-TIF regulatory protein. EMBO J. 8: 4229-4238.

Kristie, T.M., J.L. Pomerantz, T.C. Twomey, S.A. Parent, and P.A. Sharp. 1995. The cellular C1 factor of the herpes simplex virus enhancer complex is a family of polypeptides. J. Biol. Chem. 270: 4387-4394.

Kunkel, T.A., J.D. Roberts, and R.A. Zakour. 1987. Rapid and efficient site-specific mutagenesis without phenotypic sel ection. Methods Enzymol. 154: 367-382.

Lai, J.-S. and W. Herr. 1997. Interdigitated residues within a small region of VP16 interact with Oct-1, HCF, and DNA. Mol. Cell. Biol. 17: 3937-3946.

Lu, R., P. Yang, P. O'Hare, and V. Misra. 1997. Luman, a new member of the CREB/ATF family, binds to herpes simplex virus VP16-associated host cellular factor. Mol. Cell. Biol. 17: 5117-5126.

Misra, V., S. Walker, P. Yang, S. Hayes, and P. O'Hare. 1996. Conformational alteration of Oct-1 upon DNA binding dictates selectivity in differential interactions with related transcriptional coactivator. Mol Cell. Biol. 16: 4404-4413.

O'Hare, P. 1993. The virion transactivator of herpes simplex virus. The Alpha-herpesviruses. Semin. Virol. 4: 145-155.

Rose, R.E., N.M. Gallaher, D.J. Andrew, R.H. Goodman, and S.M. Smolik. 1997. The CRE-binding protein dCREB-A is required for Drosophila embryonic devel opment. Genetics 146: 595-606.

Simmen, K.A., A. N ewell, M. Robinson, J.S. Mills, G. Canning, R. Handa, K. Parkes, N. Borkakoti, and R. Jupp. 1997. Protein interactions in the herpes simplex virus type 1 VP16-induced complex: VP16 peptide inhibition and mutational analysis of host cell factor requirements. J. Virol. 71: 3886-3894.

Smolik, S.M., R.E. Rose, and R.H. Goodman. 1992. A cyclic AM P-responsive el ement-binding transcriptional activator in Drosophila melanogaster, dCREB-A, is a member of the leucine zipper family. Mol. Cell. Biol. 12: 4123-4131.

Suzuki, N., W. Peter, T. Ciesiolka, P. Gruss, and H.R. Schöler. 1993. Mouse Oct-1 contains a composite homeodomain of human Oct-1 and Oct-2. Nucleic Acids Res. 21: 245-252.

Thompson, C.C. and S.L. MCKnight. 1992. Anatomy of an enhancer. Trends Genet. 8: 232-237.

Wilson, A.C., K. LaM arco, M.G. Peterson, and W. Herr. 1993a. The VP16 accessory protein HCF is a family of polypeptides processed from a large precursor protein. Cell 74: 115-125.

Wilson, A.C., M.A. Cleary, J.-S. Lai, K. LaM arco, M.G. Peterson, and W. Herr. 1993b. Combinatorial control of transcription: The herpes simplex virus VP16-induced complex. Cold Spring Harbor Symp. Quant. Biol. 58: 167-178.

Wilson, A.C., J.E. Parrish, H.F. Massa, D.L. N elson, B.J. Trask, and W. Herr. 1995a. The gene encoding the VP16-accessory protein HCF (HCFC1) resides in human Xq28 and is highly expressed in fetal tissues and the adult kidney. Genomics 25: 462-468.

Wilson, A.C., M.G. Peterson, and W. Herr. 1995b. The HCF repeat is an unusual proteolytic cleavage signal. Genes \& Dev. 9: 2445-2458.

Wilson, A.C., R.N . Freiman, H. Goto, T. Nishimoto, and W. Herr. 1997. VP16 targets an amino-terminal domain of HCF involved in cell cycle progression. Mol. Cell. Biol. 17: 6139-6146.

Wu, T.J., G. Monokian, D.F. Mark, and C.R. Wobbe. 1994. Transcriptional activation by herpes simplex virus type 1 VP16 in vitro and its inhibition by oligopeptides. Mol. Cell Biol. 14: 3484-3493. 


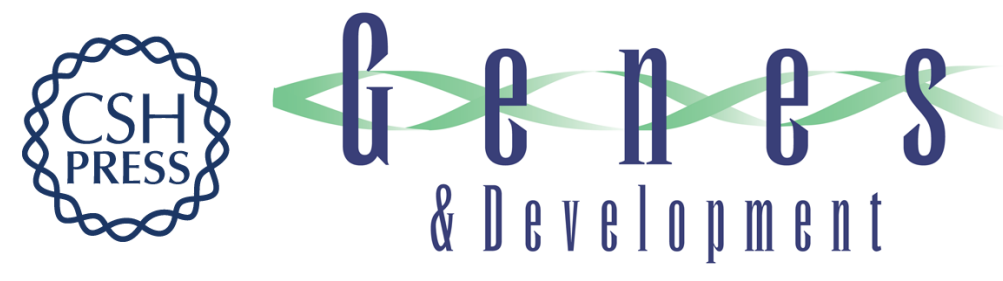

\section{Viral mimicry: common mode of association with HCF by VP16 and the cellular protein LZIP}

Richard N. Freiman and Winship Herr

Genes Dev. 1997, 11:

Access the most recent version at doi:10.1101/gad.11.23.3122

References

This article cites 28 articles, 17 of which can be accessed free at: http://genesdev.cshlp.org/content/11/23/3122.full.html\#ref-list-1

\section{License}

Email Alerting

Receive free email alerts when new articles cite this article - sign up in the box at the top Service right corner of the article or click here.

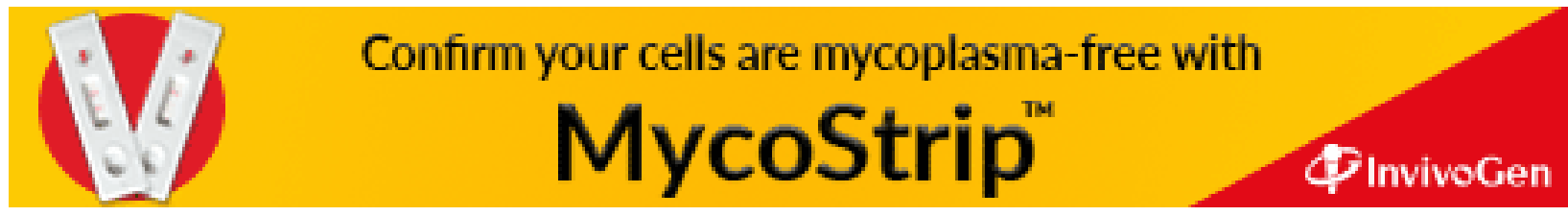

